\title{
JOHN MAYNARD KEYNES E MACROECONOMIA DAS DECISÕES CAPITALISTAS: NA PERSPECTIVA DA TEORIA ECONÔMICA MONETÁRIA DA PRODUÇÃO
}

Stéphani Cetimia Mariotti Ruiz ${ }^{1}$

RESUMO: O artigo apresenta as contribuições de John Maynard Keynes para compreensão do sistema capitalista, de forma a evidenciar seus estudos revolucionários que contribuíram para modificação da visão clássica e irreal das economias e as relações de decisão da economia. Caracterizando a economia mundial baseada no poder de liquidez, ou seja, a teoria econômica monetária da produção. O estudo proporciona uma explicação sucinta sob a relação dos fatores para tomadas de decisões dos capitalistas e suas influencias na hierarquia das decisões da economia e as reformas sociais propostas por Keynes. Finalizando com a valorização dos estudos de Keynes e a introdução da crítica do economista Minsky sobre o Keynesianismo convencional, a sua fragilidade financeira e a argumentação que para Keynes a economia capitalista era composta por ativos, Minsky evolui essa explicação e evidencia que a economia é composta por ativos que são financiados por passivos em um balanço de contrapartida.

Palavras-Chave: Keynes; Hierarquia; Capitalismo; Reforma social.

\section{JOHN MAYNARD KEYNES AND MACROECONOMY OF CAPITALIST DECISIONS: FROM THE PERSPECTIVE OF MONETARY ECONOMIC THEORY OF PRODUCTION}

\begin{abstract}
The article presents John Maynard Keynes' contributions to the understanding of the capitalist system in order to highlight his revolutionary studies that contributed to the modification of the classical and unrealistic view of economies and the decision relations of economics. Characterizing the world economy based on liquidity power, i.e. the monetary economic theory of production. Thus, the article provides a brief explanation of the relationship of capitalist decision-making factors and their influence on the hierarchy of economic decisions and the social reforms proposed by Keynes. Concluding with the appreciation of Keynes's studies and the introduction of economist Minsky's critique of conventional Keynesianism, its financial fragility and the argument that for Keynes capitalist economy was composed of assets, Minsky evolves this explanation and shows that economics is composed. by assets that are financed by liabilities in a counterpart balance.
\end{abstract}

Keywords: Keynes; Hierarchy; Capitalism; Social Reform.

\footnotetext{
${ }^{1}$ Mestranda em Desenvolvimento Econômico pela Universidade Estadual de Campinas (UNICAMP), Instituto de Economia (IE) com área temática em Economia Agrícola e do Meio Ambiente. Bacharel em Administração de Empresas com ênfase em Agronegócios pela Universidade Estadual Paulista (UNESP).
} 


\section{INTRODUÇÃO}

John Maynard Keynes, britânico, reformista, heterodoxo e singular em seus estudos sobre a teoria econômica, idealizava a economia como um instrumento de política, com a preocupação na sociedade formada pelas pessoas "comuns". O marco da implementação dos seus estudos foi após a crise 1929, pois colocou em pauta o modo pelo qual os economistas clássicos, pensadores ortodoxos aplicavam teorias para o funcionamento da economia voltadas para modelos estáticos, com racionalidade substantiva, mecanismos de mercado livre e a livre interferência ideologia (mão invisível). Mas o pensamento de Keynes rompeu essa ideologia estática e irreal, informando sobre a necessidade de modificação do modo de pensar em economia, mostrando a importância de estudos de modelos reais. Incentivando uma reforma social necessária para que a economia pós-crise de 1929 volta-se a funcionar e beneficiar todos na sociedade (BELLUZZO, 2016; 2004).

Keynes considerava que as flutuações na economia prejudicavam a todos, mas as pessoas de baixa renda eram os mais prejudicados, assim, mostrando que os problemas sociais precisavam ser vistos pela economia e inseridos nas pautas de desenvolvimento econômico. Rompendo os objetivos individualistas dos capitalistas e mostrando a importância do aperfeiçoamento humano para o desenvolvimento "saudável" da economia nacional, ou seja, o ser humano passa a ser visto não mais como o homo economics ("love of money"), motivado exclusivamente pelo dinheiro), mas sim o indivíduo com cultura e história, que influencia nas suas tomadas de decisão (KEYNES, 1936; BELLUZZO, 2016).

Assim, em seu principal livro "A Teoria Geral do emprego, do juro e da moeda" no capitulo 17, Keynes mostra que a essência da grande depressão de 1929, foi ocasionada por esses fatores apresentados anteriormente, mas além disso, pela posse da riqueza, ou seja, a economia capitalista se movia pela acumulação de riquezas monetárias em suas formais mais liquidas possíveis, e não pela idealização clássica que seria movida pela acumulação de riquezas em sua forma de bens reais. Assim, se iniciou a teoria econômica monetária da produção, rompendo de vez com as ideologias clássicas ortodoxias da economia de equilíbrio e busca pela produção de bens (KEYNES, 1936; BELLUZZO, 2016). 
Com isso, Keynes inicia uma jornada em seus estudos para mostrar ao mundo a importância da reformulação das economias mundiais, pois o método que estava sendo implementado visava uma crise que poderia não ser superada. Assim, obteve-se a crise de 1929 nesse contexto apresentado. Deste modo, Keynes se dedicou a formulação de uma teoria geral que pudesse transformar ou reformar as economias com face ao desenvolvimento continuo com foco em não geração de crises. Iniciando pela explicação do mundo real capitalista através explicação da teoria economia monetária da produção como compreensão do objetivo principal, a importância da moeda (POLARI, 1984; FERREIRA, 2008; FONSECA, 2010).

Assim, os bens teriam um preço em forma monetária, ou seja, troca monetária, não mais como fuma forma de economia de escambo (fisiocratas), mas sim, a moeda (dinheiro) como funcionamento de interesse intermediário e principalmente o objetivo final da produção. Ou seja, o dinheiro como forma e objetivo central dos capitalistas. Pois, Keynes expunha que a liquidez da riqueza era forma mais desejada pelos capitalistas, assim, em um ambiente que não possui equilíbrio, assim um ambiente de mercado encharcado de incertezas, os tomadores de decisão visavam a liquidez como segurança para a obtenção de fortunas, mostrando que a relações capitalistas não seria mais a busca pela produção exclusiva de mercadoria, mas sim a mercadoria como um intermediário apenas (FERREIRA, 2008; BELLUZZO, 2016).

A economia empresarial, buscava a existência de outros usos da moeda, sem ser obrigatória usá-la na aquisição de produção, mas também em bens de investimento, essencialmente ter expectativa positiva de rendimento, com resultados monetários (ganhos que terá), objetivo principal do proprietário de riqueza, interessado na quantidade de moeda que ganhará. Formulando a teoria economia monetária da produção, representada pela simples expressão: [Dinheiro -> Mercadoria -> Mais Dinheiro (D-M-D')] (KEYNES, 1933).

Com isso, a moeda era o símbolo desse empasse, como ativo de riqueza, os proprietários precisam tomar decisões sobre alocação de recursos, com o portfólio de escolhas. Entretanto, muitas escolhas não geram emprego ou riquezas a sociedade como um todo. Nesse ponto que inicia a preocupação de Keynes, pois os proprietários querem liquidez absoluta de suas riquezas, ou seja, capacidade de rapidez na transformação em moeda e sem perda de valor. Porém, nesse percurso poderia haver o não investimento em bens de capital (como investimento produtivo 
macroeconômico, que geram emprego e renda a sociedade), gerando a não produção de capital produtivo, enfraquecendo as economias reais e apenas fortalecendo os rentistas com capital de aplicação financeira (não gera riqueza macroeconômica) (KEYNES, 1933; FERREIRA, 2008; BELLUZZO, 2016).

É importante salientar que para a aplicação dessa teoria de forma a gerar uma reforma social, o estado seria fundamental para ponderação das decisões dos capitalistas. A necessidade que o Estado substitua a ação individual dos capitalistas, para não geração de crises posteriores, pois o sistema capitalista não seria estável. Assim, depois da crise de 1929, o sistema não teria poder mais de autorregularão plena, gerando a necessidade dos governos em socializar o investimento produtivo. Ou seja, o Estado volta a participar com mais intensidade, com atuações nas subidas de gastos sociais e elevação dos tributos para geração de riquezas sociais. Assim, após a implementação da teoria econômica não clássica de Keynes, as nações não sofreram mais tais danos da depressão gigantesca de 1929 e o pós segunda guerra mundial (FERREIRA, 2008; BELLUZZO, 2016).

Entretanto, a instabilidade é real no sistema capitalista, por isso existe a necessidade da intervenção estatal. Neste breve contexto, nas sessões seguintes será explicado mais a fundo a teoria monetária da produção, o conceito de demanda efetiva para melhor compreensão da relação de emprego, a hierarquia das decisões na teoria monetária da produção, a reformar proposta por Keynes para o sistema capitalista; e por fim, as considerações finais sobre a importância das teorias de Keynes e sua contribuição para a nova dinâmica econômica após 1929, uma breve apresentação dos pós-keynesianos e suas contribuições para teoria econômica monetária, além da crítica minskyana em relação a instabilidade financeira e o poder dos bancos no sistema capitalista.

\section{TEORIA ECONÔMICA MONETÁRIA DA PRODUÇÃO}

Neste contexto apresentado até o momento, identificou a importância da teoria econômica monetária da produção (1933) desenvolvida por Keynes e seus fundamentos principais. Deste modo, no seu prefácio da Teoria Geral do Emprego, do Juro e da Moeda, Keynes (1936) apresenta o dilema da economia monetária de como o volume de emprego se entrelaça com as expectativas de lucro definidos por 
gastos dos capitalistas. Assim, o problema no qual a relação econômica entre o emprego das massas e a obtenção de liquidez pelos capitalistas no investimento em ativos menos líquidos (bens de capital), pois os tomadores de decisão não querem investem nesse tipo de bem, ou seja, realizar investimento produtivos, devido principalmente a liquidez do momento ou rendimentos esperado espetacular para abrir mão da liquidez imediata em relação ao tempo.

Essa observação volta a incorporar a necessidade do papel intervencionista do Estado, pois em seu estudo anterior a publicação da teoria geral, Keynes em 1934 publica o "Poverty in plenty: Is the economic system self - adjusting?", mostrando que não existe mecanismo de ajustamento automático para esse dilema sobre investimento financeiro ou produtivo. Para Keynes se houver o investimento produtivo transformaria a pobreza em crescimento pleno, entretanto, isso não acontece sem ajuda motora de ações do Estado, como por exemplo: regulação financeiras, interferência nos preços por taxas de juros, benefícios fiscais e etc.), supondo um Estado com muitas informações suficientes para atuação de qualidade e para os aspectos do pleno emprego.

Deste modo, retomando a perspectiva da teoria da economia monetária da produção, que visa a liquidez em forma de moeda (dinheiro), na transformação do dinheiro em mercadoria e posteriormente em dinheiro com lucros extraordinários. Assim, o dinheiro como fim de si mesmo e o proprietário do dinheiro com objetivo de sempre será a obtenção do dinheiro para possuir sempre mais dinheiro. Observa assim, a economia da circulação (do mundo real), cujo a moeda não seria apenas um facilitador de circulação ou troca real de mercadoria, mas um objeto de desejo e de tomada de decisão para liquidez imediata.

$E$ as consequências disto são a possibilidade de ocorrência de desemprego involuntário em massa, pois o pleno emprego pode não ser vantajoso em termos monetários para os tomadores de decisão (capitalistas), a produção de determinada quantidade que suporte os lucros extraordinários para o capitalista pode gerar um nível de desemprego, gerando supostamente uma deficiência de demanda, ocorrendo o emprego involuntário, pois nada garante que a produção de determinada quantidade de um bem " $X$ " gere o pleno emprego. Assim, o desemprego decorre de um funcionamento normal de uma economia monetária capitalista (KEYNES, 1933). 


\subsection{DEMANDA EFETIVA}

O desemprego por sua vez está no linear das hierarquias de decisões capitalistas, ou seja, ligado inicialmente pela relação com a demanda efetiva. A demanda efetiva que se conecta com a decisão de gastos é deficiente quando não gera o pleno emprego. Pois o gasto que cria a produção, emprego e renda, não necessariamente cria a demanda efetiva. Assim, as decisões de gasto versos expectativas de lucro/rendimento monetário sob uma produção para ter mais ou menos emprego. O uso da moeda é a condição necessária para flutuações na demanda efetiva, pois ela não pode ser parte da produção corrente, pode remunerar a produção, não é uma moeda neutra (pois não existe o pleno emprego, devido a tomada de decisão de produzir determinada quantidade por escolha de expectativas de lucro) e a moeda é endógena, ou seja, estabelecida fora do sistema produtivo (KEYNES, 1936; KLAGSBRUNN et al, 1996).

Em relação demanda efetiva nota-se então que o volume de emprego depende do nível esperado de ganhos que os capitalistas (ou empresários) esperam ganhar da totalidade da produção produzida, assim, em relação ao emprego, o número de trabalhadores que precisara trabalhar para produção de bens depende das expectativas de venda das mercadorias dos empresários e a obtenção de lucros sobre a venda. Ou seja, o emprego real está associado a propensão a consumir da demanda, além do nível de investimento que determinara o nível de emprego e consequentemente o nível dos salários reais. Essa hierarquia mostra então que o consumo e o investimento determinam a demanda efetiva que posteriormente determinará o total de empregos (que por sua vez todas essas decisões são determinadas pelo capitalista na sua tomada de decisão pautada na liquidez monetária) (KLAGSBRUNN et al, 1996).

$O$ investimento é o ponto central em relação a demanda efetiva, pois o consumo sempre cresce em uma proporção menor que o da renda, determinando assim, que a renda da população depende do volume de emprego, que consequentemente o consumo só é gerado dependendo da renda (com exceção da existência de uma mudança na propensão a consumir determinado bem). Assim, o desemprego involuntário não é caracterizado como uma função estrutural, mas sim, das expectativas da demanda efetiva, ou seja, existe a assimetria de poder entre os 
empregados, que não possuem poder de estabelecer o preço e quantidade, essa função é dos empresários, e por consequência os gastos que geram a renda (KEYNES, 1936; KLAGSBRUNN et al, 1996).

\subsection{HIERARQUIA DAS DECISÕES NA TEORIA MONETÁRIA DA PRODUÇÃO}

No desenvolvimento da "Teoria Geral do emprego, do juro e da moeda" (1936) de Keynes, o enfoque norteador e essencial se pauta na dependência que o nível de emprego da economia tem em relação a função a oferta agregada, a propensão ao consumo e não menos importante a decisão de investir. Assim, a importância que a economia capitalista verifica é de que o princípio de obtenção de mais dinheiro é o motor dessa relação, identificando o nome de sua teoria, ou seja, monetária, porque ela é o início, se possível, o meio e com grande certeza o fim desejado, sempre acrescendo de lucros para aumento em relação ao início desse ciclo, ou seja, economia capitalista feita para ganhar mais e mais dinheiro, não necessariamente o bem social ou a produção de bens de capital.

Nesta perspectiva originaria marxista que Keynes, nas "entrelinhas" utiliza para concepção da teoria monetária, ressalva que a economia monetária da produção não leva ao pleno emprego, devido ao seu objetivo central de possuir dinheiro, gerando mercadoria para obtenção de mais dinheiro [ "Se não fosse preciso criar mercadoria, não seria criada e sim, a relação seria dinheiro se transformando em mais dinheiro, ou seja, o "extremo do capitalismo"].

Como Keynes era um reformista social em sua essência, mas não com enfoque em "destruir" o capitalista, mas sim transforma-lo para seguir caminhas mais sustentáveis, utilizando de políticas econômicas para melhoramento desse sistema. Assim, de certa forma, Keynes queria "Encapsular o sistema capitalista" de forma que pudesse controlá-lo (POLARI, 1984).

A partir dessa explicação sobre a visão de Keynes, o sistema capitalista e a sua teoria econômica monetária da produção, em seu estudo da teoria geral (1936) apresentado em capítulos, os estudiosos de sua teoria, incrementam que a teoria geral foi escrita de "trás para frente", ou seja, que na verdade, Keynes deveria (poderia) ter organizado seus capítulos do fim para o começo. Pois a sua complexidade explicativa se tornaria mais facilmente compreensível pelos leitores. Observações a parte, para explicação da hierarquia das decisões na teoria 
monetária da produção, utilizei essa crítica positiva dos leitores e estudiosos para explicação dessa fantástica complexidade de tomadas de decisões que são ponderadas por decisões superiores a cada uma delas. Ou seja, a decisão sob a riqueza como o poder central da relação com as outras decisões seguidas pela decisão sob os juros, depois sob investimento, consumo, produção e pôr fim a decisão sob o emprego (KEYNES, 1936).

Figura 1 - Hierarquia das decisões da teoria da economia monetária da produção por Keynes.

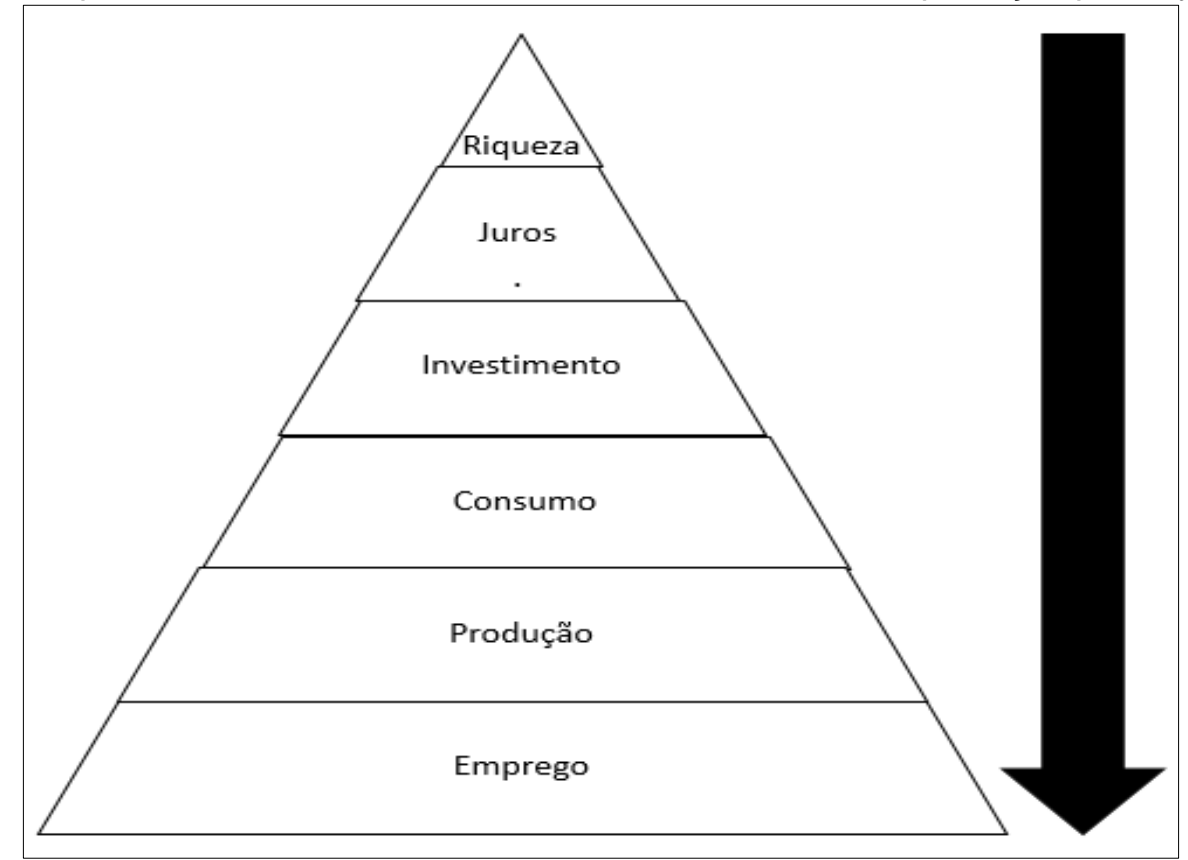

Fonte: Elaborado pela autora.

A partir da pirâmide de decisões capitalistas, observa-se que o argumento da macroeconomia clássico (mainstream), pautado na hipótese de que "se equilibra no emprego total da sociedade, ou seja, o pleno emprego" não seria real, devido a hierarquia de decisões sobre expectativas de rendimentos futuros.

\subsubsection{Emprego}

Em relação a decisão sob o emprego, caracterizada como a decisão de última instância, observa-se que essa decisão de torna a que menos influencia na economia monetária da produção. Pois, a população praticamente não realiza essa decisão, devido a submissão em relação a hierarquia das decisões. Nesse sentido, quem impõe os níveis de emprego, diretamente é a decisão de produzir, se não 
houve essa decisão, consequentemente não haveria a decisão de emprego. Tornado assim a evidência que o emprego não tem relação com o mercado de trabalho, ou seja, a decisão de emprego é tomada pela decisão empresarial de produzir e não pela população ou melhor dizendo pelos valores salarias. Evidenciando que a decisão sob o emprego advém da decisão de produzir (KEYNES, 1933; 1936).

\subsubsection{Produção}

Já as decisões sob produção são regidas por antecipação do futuro. Pois para Keynes, as decisões em geral na economia capitalista eram pautadas na perspectiva de futuro, ou seja, em outras palavras uma economia de "expectativas", com essa perspectiva, evidencia a quebra do paradigma clássico do mundo irreal sobre as decisões, pois mesmo sendo tomadas em presente, as expectativas sob o futuro que norteiam as decisões do presente (KEYNES, 1933; 1936)..

Neste contexto, é notável essa explicação de Keynes, pois as decisões dos empresários (ou donos das riquezas) levam a perspectiva de futuro em consideração, pois o futuro que irá proporcionar rendimentos para essa decisão de produzir no momento presente, assim, decisões do futuro sempre para trazer ao presente. Esse comportamento é gerado principalmente pela dificuldade de fixar regras no mercado, ou seja, como agir em um ambiente competitivo e de grandes incertezas constantes e inerentes as decisões, que precisariam ter regramento de apoio para tomadas decisões, por isso conceituasse o indivíduo capitalistas (empresário) como um sujeito especulativo (KEYNES, 1933; 1936).

Criando um sistema capitalista de administração de expectativas, cuja decisão de produzir determinado bem dependerá da avalição do empresário em "curto prazo" sob os rendimentos esperados e a quantidade vendida de um bem, assim, estimando uma demanda esperado em relação ao bem ou serviço, além da curva de oferta caracterizado pelo mínimo de retorno que se pode tendência a ter (KEYNES, 1933; 1936; ALMEIDA; BELLUZZO, 2012).

Nesse ponto, retoma-se a questão. Qual então será a demanda da produção? Seria apenas especulativa? Segunda Keynes a resposta seria relacionada com a demanda efetiva do produto, como já apresentado na sessão anterior. Assim, a rentabilidade esperada da produção, ou seja, a decisão de produzir que pautará a 
decisão de emprego em curto prazo que a antecipação da decisão de produzir e rentabilizar, para que assim emprego determinado nível de empregabilidade. Neste ciclo, não necessariamente o emprego e a produção diminuem a demanda efetiva, podendo ser respondida pelo ciclo do estoque também.

Com tudo, para estabelecer a nível de produção que influenciará no nível de emprego, em curto prazo os empresários utilizam o método de tentativa e erro, por não possuírem certezas futuras e nem informações simétricas sobre todas as relações de mercado. Assim, a avaliação da demanda efetiva, é a antecipação da demanda de bens de capital e do consumo que geram a decisão de produção, ou seja, a decisão de produção não é autônoma, dependendo então da decisão empresarial de investir recurso e do público em consumir. Evidenciando que a decisão de emprego é a última a se conceber, ou seja, a decidir e não se baseando no aumento ou diminuição dos salários (ALMEIDA; BELLUZZO, 2012).

\subsubsection{Consumo}

A partir da decisão de produção do empresário, como antecipação do consumo da sociedade; o consumo é fundamental para decisão de produzir e consequentemente do emprego, ou seja, afirmando a ideia de mercado "que não adianta produzir e não vender". Assim, se a demanda efetiva for baixa (imaginada pelos empresários sob suas expectativas), evidencia que o consumo foi maior que a produção, entretanto, se o empresário aumentar a produção, quem garantirá que a haverá mudanças reais na demanda efetiva? Afirmando novamente que a economia não é estática, ou seja, que a certeza não é concreta e que o nível de emprego, de produção e de demanda efetiva são dinâmicos, e ainda são influenciados pela hierarquia das decisões de investimento, taxa de juros e primordialmente pela riqueza (monetária) (KEYNES, 1933; 1936).

Neste interim, o consumo influência a produção e em seguida o emprego, ou seja, o consumo se pauta na lei da psicologia fundamental, cuja evidencia que com um aumento na renda disponível gera um aumento no consumo, entretanto, com o aumento da renda também pode ocasionar uma poupança desse recurso. $O$ ciclo do consumo que também pode ser influenciado pelo padrão de consumo e por propagandas de marketing, mostra que o próprio consumo não é autônomo, 
influenciado pelo investimento, pois está ligado a renda. Nesse ponto, Keynes faz uma subestimação sobre aa atuação dos bancos e a oferta de crédito (será aprofundado nas considerações finais), mas mesmo assim, o nível de renda é parâmetro de crédito, consequentemente do consumo. Assim, como a renda influencia o consumo e a renda é uma função do investimento, concluindo então que a decisão de consumo está interligada diretamente a decisão sob investimento. (KEYNES, 1933; 1936; ALMEIDA; BELLUZZO, 2012).

\subsubsection{Investimento}

Nesse patamar da pirâmide das decisões capitalistas, o investimento é caracterizado pela sua autonomia. Ou seja, para Keynes o investimento determinado a poupança, mas como já citado, Keynes (nesse momento) não assumiu que os bancos ofertam crédito, "apostando" no planejamento do empresário sem levar em consideração necessariamente a renda real do empresário. Entretanto, Keynes faz uma reflexão coerente, cuja a solução seria investir para influenciar na elevação do nível de emprego, na produção, no consumo e em na poupança. Neste ponto que a intervenção estatal se torna mais importante, pois os poderes do Estado e as políticas públicas necessariamente precisam influências no nível de investimento para geração de emprego (KEYNES, 1933; 1936).

Entretanto, a decisão de investir para gerar aumento de do nível do emprego é a incógnita principal de interferência do Estado, pois o rendimento desse investimento precisa ser desejado pelo empresário, assim, o investimento em bens de capital (produtivo) pode não despertar esse deseja esperado do empresário, pois existe a alternativa da rentabilidade financeira, cuja gera riquezas ao rentista, mas não necessariamente emprego (KEYNES, 1936; ALMEIDA; BELLUZZO, 2012)..

Assim, o investimento é "querer" ter uma riqueza real (produtiva) e não abstrata como os rentistas que usufrui de juros. Com isso, o tomador de decisão considera o sentido de investir com a compra de um bem que em sua "vida útil" gere rendimentos para ele, ou seja, o investimento é baseado em fatores que são incapazes para determinar exatamente o seu retorno, evidenciando mais uma vez que a economia capitalista é baseada em expectativas (KEYNES, 1936; ALMEIDA; BELLUZZO, 2012). 
Assim, o investimento é dependente da taxa de juros sob a rentabilidade do rendimento, levando a afirmativa que a rentabilidade precisa ser superior a taxa de juros vigente no mercado, descrevendo a eficiência marginal do capital (rentabilidade esperada do bem de capital ao longo de sua vida útil). Nota-se então, que a expectativa de futuro capitalista é ligada pelo investimento no presente, e que nessa relação, a decisão de investimento não modifica do futuro para o passado, não possui um grau de modificação igual à decisão de produzir que pode ser modificada no curto prazo.

A expectativa em longo prazo influência na decisão sob juros, pois a incerteza das taxas de rentabilidade de longo prazo estão associadas a incerteza radical, que no sistema capitalista significa que não possuem probabilidade ou parâmetros, ao contrário do significa de risco, que vincula parâmetros probabilísticos históricos de avaliação do futuro, porém falando de um regime capitalista a incerteza é inerente ao processo de decisões, pois como Keynes já caracterizou, " a economia capitalista é caracterizada como a economia das expectativas do futuro em um ambiente de incertezas".

Entretanto, mesmo caracterizando dessa maneira o sistema capitalista, Keynes cria a chamadas "convenções", instrumentos que servem como parâmetros aceitos para guiar os investimentos, ou seja, tentativas de estabelecer parâmetros que não são probabilísticos, relacionando com os concorrentes setoriais, assim, convenções para o sistema funcionar e diminuir o "caos" da incerteza, ou seja, minimamente para que os empresários diminuam suas incertezas e os mercados financeiros podendo definir o otimismo e o pessimismo no realização de investimento, gerando confiança empresarial.

Mas como o investimento é considerado a ligação que temos com o futuro, mesmo com as convenções e a administração dos mercados financeiros sobre as antecipações, ainda existe a incerteza (ALMEIDA; BELLUZZO, 2012).

\subsubsection{Juros}

A taxa de juros influência nas antecipações do futuro para realização do investimento, assim é a arma da interface da riqueza, pois é determinado pelos ativos e não se caracteriza como uma função da demanda efetiva. Ativos esses, 
caracterizado como a demanda por moeda (dinheiro), porém a moeda é um fator exógeno ao processo, pois a moeda não faz parte da produção, ou seja, é ofertada, criada e controlada pelo Banco Central emissor (KEYNES, 1933; 1936).

Assim, a teoria econômica monetária da produção de Keynes evidência sempre o desejo pelo dinheiro. Mas o dinheiro não se produz no sistema produtivo, o emprego não gera o dinheiro, identificando que o complexo do sistema é "como chegar no poder do dinheiro?". Ou seja, para ter dinheiro tem que passar por todas as fases, pelo emprego, pela produção e pelo investimento que é influenciado pela taxa de juros.

Assim, Keynes também separa dos ativos em dois tipos: o primeiro como ativo produtivo, cujo aquele gera alguma produção e o segundo, que não gera rentabilidade, não produz nada em si, mas sim, a característica mais deseja de um capitalista, a liquidez. Entretanto, todo ativo possui um custo de logística e de grau de liquidez, mas não terão produtividade do investimento. Assim, o dinheiro em si não tem nenhuma dessas características de ativos (retorno e custo de carregamento), mas apenas o atributo da liquidez. (ALMEIDA; BELLUZZO, 2012; FERREIRA, 2018).

\section{REFORMA PROPOSTA POR KEYNES PARA O SISTEMA CAPITALISTA}

A partir da elaboração da teoria econômica monetária da produção, Keynes proposto quais mudanças (reformas sociais) seriam necessárias para modificação da lógica baseada no fator trabalho não sendo protagonista e a distribuição de renda. Ou seja, Keynes visava uma reforma no sistema capitalista para melhorar o seu funcionamento, favorecendo os trabalhadores e a geração e investimento produtivo. Com essa reforma social pautada em políticas econômicas e interferência estatal na economia, propondo então uma proposta de administração direta do capitalista, em outras palavras "Keynes queria encapsular o sistema capitalista" (KEYNES, 1936).

A proposta da "eutanásia do rentista" é caracterizada como a ação de eliminação dos indivíduos que não geram riquezas produtivas, cujos apenas usufrui dos rendimentos de investimentos já existentes, com a relação da taxa de juros. Assim, Keynes propõe a diminuição das taxas de juros para tentativa de aniquilação dos rentistas. Entretanto, mesmo com esse radicalismo explicitado por Keynes, ele 
não era contra os bens afortunados (os ricos), mas a proposta era que o rico poderia ser rico, mas que não vivesse da renda dessa riqueza sem a produção produtiva, ou seja, a necessidade de usar a riqueza para gerar produto (emprego), assim, a proposta era acabar com o rentista que não produzem e que geram apenas rentabilidade própria (indivíduo que vive apenas dos ganhos de juros). Keynes propõe também a utilização da política tributária para a realização da tributação das riquezas das grandes fortunas e herança (FERREIRA, 2018; BELLUZZO, 2016).

A propensão ao consumo (gasto social) surge como incentivo ao aumento do consumo da população através da redistribuição de renda das riquezas públicas, ou seja, aumentando a renda da sociedade como um todo, aumentaria o consumo de bens e serviços, consequentemente aumentaria o emprego e diminuiria a desigualdade da distribuição de renda. E a socialização do investimento, condição do investimento público que possa incentivar realizações de investimentos privado. Ou seja, realização de programas de investimento governamental a longo prazo para "despertar" o interesse do investimento privado (Exemplo do Brasil seria o programa de seguridade social - INSS). Assim, organizar um orçamento do investimento público e consequentemente privado para gerar investimento agregado para diminuir os rentistas e diminuir o problema da distribuição de renda. (KEYNES, 1933; 1936, BELLUZZO, 2016).

Desta forma, Keynes informa a necessidade da socialização do investimento, de ter um ótimo sistema tributário, redistribuição de renda, taxa de juros mais delimitadas (para não possuir individuas que vivam exclusivamente de renda) (KEYNES, 1936).

\section{CONSIDERAÇÕES FINAIS}

Em suma, a teoria geral de John Maynard Keynes fornece a compreensão de forma holística sobre o funcionamento o sistema capitalista no mundo real. As contribuições de Keynes também proporcionaram uma nova dinâmica econômica após a crise de 1929, cuja várias nações pelo mundo utilizaram de sua teoria para execução de políticas e ações para saída da crise, com atitudes voltadas a intervenção estatal e a valorização do emprego e o setor produtivo, gerando um marco histórico na teoria econômica mundial. Entretanto, os ensinamentos de 
Keynes para a atualidade precisam ser recontextualizados, pois Keynes realizou gigantescos avanços para os problemas de sua época, a necessidade de reinventar a o plano de Keynes para a economia internacional é fundamental para evolução da economia.

Além disto, Keynes em sua teoria geral das hierarquias das decisões na teoria monetária da produção, não considerou o poder dos bancos na interferência da determinação da taxa de juros, ou seja, não evidenciou que o sistema bancário fosse mais que um intermediário de crédito, mas sim, um agente poderoso na relação com a riqueza e a liquidez tão deseja vinda da obtenção do dinheiro, porém mais tarde, ele reconhece as características bancária em um artigo. Pois a importância do setor bancário na relação capitalista atualmente se torna imprescindível, devido a sua interferência no investimento (principal decisão para geração de poupança, emprego, produção e consumo), assim, os bancos administram as riquezas e os juros, gerando uma grande interferência no sistema capitalista.

Desta forma, é importante evidenciar outro autor subsequente a Keynes que de forma inteligente proporcionou estudos que buscava o de mais fantástico e revolucionário que Keynes escreveu para aprofundar na compreensão do sistema capitalista, seu nome foi Hyman Philip Minsky. Cujo, utilizou principalmente do capítulo 17 "As Propriedades Essenciais dos Juros e do Dinheiro" do livro da Teoria Geral do Emprego, do Juro e da Moeda de Keynes de 1936, para explicação da inserção da endógena a fragilidade financeira.

Em seu livro "Stabilizing an unstable economy" (1986) e John Maynard Keynes (1975) Minsky, evidencia a importância da teoria monetária da produção de Keynes, porém Minsky, com sua genialidade, complementa Keynes na definição do sistema capitalista, que não seria apenas composto por ativos, mas Minsky caracteriza a economia capitalista com um conjunto de balanços entrelaçados, ou seja, método de partilha dobrada. Assim, a economias capitalistas seria uma economia de endividamento, como uma economia com financiamento minimamente desenvolvido com variação de características no tempo e no espaço com a transformação das estruturas financeiras. Pois, a riqueza capitalista é detentora de ativos e suas decisões de alocação de ativos em relação ao retorno total, assim, alteram o portfólio mediante o retorno total, concluindo então que cada um dos ativos possui um passivo correspondente, ou seja, Minsky evidência que a economia 
é de dividas, pois existe financiamento (próprio ou de terceiros) para tudo (GERIONI, DEOS, 2018; NAPPI, DEOS, MENDONÇA, MATTOS, 2018).

Minsky consegue ir além de Keynes, mostrando que a economia capitalista possuí a fragilidade financeira advinda da lógica que sempre que as decisões de gastos são financiadas, introduz então uma instabilidade, podendo gerar uma crise no sistema [como geralmente é observado]. Pois tudo se baseia no valor do bem especulativo do futuro, assim, causando tendenciosidade de crises, além das inovações financeiras na economia capitalista, que geram o "boom" e proporciona também a fragilidade financeira. Assim, Minsky de certa forma instabiliza a teoria institucionalista de Keynes (DEOS; MENDONÇA, 2017).

Portanto, a teoria econômica monetária da produção, a hierarquia das decisões capitalistas e as reformas sociais de Keynes contribuiu (muitíssimo) para as nações "enxergarem" a economia como precisaria ser vista e interpretada, principalmente em sua época (da crise de 1929 e o pós segunda guerra mundial). Entretanto, seus estudos foram reformulados e introduzidos variáveis importantes para as economias mais atuais, como apresentado a evolução da teoria economia Keynesiana por Minsky, cujo contribui muito para observarmos a importância do sistema bancário nas relações da hierarquia das decisões capitalistas, do estabelecimento da contrapartida dos ativos com o financiamento pelos passivos e a tendência a crises e a importância de políticas para diminuir as consequências dos "booms econômicos".

\section{REFERÊNCIAS}

ALMEIDA, J. S. G.; BELLUZZO, L. G. M. Enriquecimento e produção. keynes e a dupla natureza do capitalismo. In: Luiz Carlos Delorme Prado. (Org.).

Desenvolvimento econômico e crise. $1^{\underline{a}} \mathrm{ed}$. Rio de Janeiro: Contraponto Editora Ltda, v. 01, 2012, p. 15-25.

BELLUZZO, L. G. M. Ensaios sobre o capitalismo no século XX. Org: MAZZUCCHELLI, F. Editora UNESP, 2004, p. 239.

BELLUZZO, L. G. M. O tempo de keynes nos tempos do capitalismo. São Paulo, SP: Contracorrente, 2016, p. 124.

COUTINHO, L.; BELLUZZO, L. G. Financeirização da riqueza, inflação de ativos e decisões de gasto em economias abertas. Economia e Sociedade. v. 7, n. 2, 1998, 
p. 137-150. Disponível em:

$<$ https://periodicos.sbu.unicamp.br/ojs/index.php/ecos/article/view/8643156>. Acesso em: 20/08/2020.

DE PAULA, L. F. R. Comportamento dos bancos, posturas financeiras e oferta de crédito: de Keynes a Minsky. Análise Econômica, v. 16, n. 29, 1998, p. 21-38.

Disponível em: < https://www.seer.ufrgs.br/AnaliseEconomica/article/view/10556>. Acesso em: 20/08/2020.

DEOS, S.; MENDONÇA, A. R. R. Facing the 2008 crisis: Brazilian Central Bank and public banking system as "Minskyan" big banks. In: Christoph Scherrer. (Org.).

Public Banks in the Age of Financialization. 1 ed. Cheltenham: Edward Elgar, v. 1, 2017, p. 53-66. Disponível em:<

https://www.elgaronline.com/view/edcoll/9781786430656/9781786430656.00012.xml >. Acesso em: 20/08/2020.

FERREIRA, A. N. A recuperação pós-keynesiana da autonomia da

macroeconomia. In: Anais do XXXVI Encontro Nacional de Economia - ANPEC.

2008. Disponível em:<

http://www.anpec.org.br/encontro2008/artigos/200807202138540-.pdf>. Acesso em: 20/08/2020.

FERREIRA, A. N. Controvérsias sobre a macroeconomia de Keynes e seus possíveis fundamentos microeconômicos. Nova Economia, v. 28, 2018, p. 155-180. Disponível em:< https://www.scielo.br/scielo.php?pid=S0103-

63512018000100155\&script=sci_arttext>. Acesso em: 20/08/2020.

FONSECA, P. C. D. Keynes: o liberalismo econômico como mito. Economia e Sociedade, v. 19, n. 3, 2010, p. 425-447. Disponível em:< https://www.scielo.br/scielo.php?pid=S0104-

06182010000300001\&script=sci_arttext\&tlng=pt>. Acesso em: 20/08/2020.

GERIONI, E. M.; DEOS, S. Minsky além da instabilidade financeira. In: Anais do XI Encontro da Associação Keynesiana Brasileira: "Desafios para a Economia Brasileira: uma perspectiva Keynesiana", Porto Alegre. v. 1. 2018.

KEYNES, J. M. A monetary theory of production. CW, XIII: 408-411. 1933.

KEYNES, J. M. A Teoria Geral do emprego, do juro e da moeda. São Paulo: Nova Cultural. (1936 [1988]).

KEYNES, J. M. Poverty in plenty: Is the economic system self-adjusting? CW, XIII: 485-492. 1934.

KLAGSBRUNN, V. H. et al. O princípio da demanda efetiva (esperada) e o papel da demanda na teoria geral de Keynes. Revista de Economia Política. São Paulo, v. 16, n. 4, 1996, p. 64. Disponível em:< https://rep.org.br/rep/index.php/journal/article/view/1221>. Acesso em: 20/08/2020.

MINSKY, H. John Maynard Keynes. New York, Columbia University Press. 1975. 
MINSKY, H. Stabilizing an unstable economy. New Haven. Yale University Press. 1986 [2008].

NAPPI, J.; DEOS, S; MENDONÇA, A. R. R.; MATTOS, O. M. B. Evolução da regulação bancária no Brasil: uma análise pós-keynesiana. In: XXIII Encontro Nacional de Economia Política, Niterói, v. 1. 2018. Disponível em:< https://www.sep.org.br/anais/Trabalhos\%20para\%200\%20site/Area\%206/92.pdf>. Acesso em: 20/08/2020.

POLARI, R. S. A concepção keynesiana das crises econômicas e sua crítica com base em Marx. Revista de Economia Política Brasileira, v. 4, n. 2, 1984.

Disponível em:< https://rep.org.br/rep/index.php/journal/article/view/1888>. Acesso em: 20/08/2020. 